Original Article

\title{
The development of tag-based cooperation via a socially acquired trait
}

\author{
Emma Cohen ${ }^{\mathrm{a}, \mathrm{b}, \mathrm{c}, *}$, Daniel Haun ${ }^{\mathrm{c}, \mathrm{d}}$ \\ ${ }^{a}$ Institute of Cognitive and Evolutionary Anthropology, School of Anthropology and Museum Ethnography, University of Oxford, UK \\ b Wadham College, Parks Road, Oxford, UK \\ c Comparative Cognitive Anthropology Research Group, Max Planck Institute for Evolutionary Anthropology, Leipzig, Germany \\ and Max Planck Institute for Psycholinguistics, Nijmegen, The Netherlands \\ ${ }^{\mathrm{d}}$ Department of Psychology, University of Portsmouth, UK
}

\section{A R T I C L E I N F O}

\section{Article history:}

Initial receipt 9 May 2012

Final revision received 3 February 2013

\section{Keywords:}

Self-similarity

Child development

Cross-cultural

Accent

Brazil

\begin{abstract}
A B S T R A C T
Recent theoretical models have demonstrated that phenotypic traits can support the non-random assortment of cooperators in a population, thereby permitting the evolution of cooperation. In these "tagbased models", cooperators modulate cooperation according to an observable and hard-to-fake trait displayed by potential interaction partners. Socially acquired vocalizations in general, and speech accent among humans in particular, are frequently proposed as hard to fake and hard to hide traits that display sufficient cross-populational variability to reliably guide such social assortment in fission-fusion societies Adults' sensitivity to accent variation in social evaluation and decisions about cooperation is wellestablished in sociolinguistic research. The evolutionary and developmental origins of these biases are largely unknown, however. Here, we investigate the influence of speech accent on 5-10-year-old children's developing social and cooperative preferences across four Brazilian Amazonian towns. Two sites have a single dominant accent, and two sites have multiple co-existing accent varieties. We found that children's friendship and resource allocation preferences were guided by accent only in sites characterized by accent heterogeneity. Results further suggest that this may be due to a more sensitively tuned ear for accent variation. The demonstrated local-accent preference did not hold in the face of personal cost. Results suggest that mechanisms guiding tag-based assortment are likely tuned according to locally relevant tag-variation.
\end{abstract}

Crown Copyright @ 2013 Published by Elsevier Inc. All rights reserved.

\section{Introduction}

The most fundamental requirement for the evolution of cooperation is that the costs incurred by cooperation are offset by the benefits received from others such that a net fitness advantage is reaped relative to the population average (Fletcher \& Doebeli, 2009). In recent decades, there has been considerable theoretical and empirical progress in identifying the structuring principles and proximate psychological mechanisms guiding assortment (i.e. the non-random association of cooperators with the cooperation of others). Humans do not cooperate indiscriminately with others, but are sensitive to a range of strategic cues about prospective and past social partners' cooperative potential.

Recent modeling work in biology has demonstrated the theoretical potential for phenotypic traits to guide the assortment of cooperators in the absence of past encounters, genetic relatedness, or reputational information. In these models, genetic or cultural traits, or "tags", serve as signals of cooperative potential to prospective cooperative partners

\footnotetext{
* Corresponding author. Max Planck Institute for Psycholinguistics, Wundtlaan 1, 6525XD Nijmegen, Netherlands.

E-mail address: emma_cohen@eva.mpg.de (E. Cohen).
}

(Antal, Ohtsuki, Wakeley, Taylor, \& Nowak, 2009, Jansen \& van Baalen, 2006, Masuda \& Ohtsuki, 2007, Riolo, Cohen, \& Axelrod, 2001).

In similarity-based models, for example, individuals cooperate with others whose tags are similar to their own. Insofar as signals are reliable (i.e. robust against invasion by free-riding individuals who bear the tag but do not cooperate), tag-based cooperation can evolve and be sustained in a population of unrelated individuals that is otherwise composed of indiscriminate cooperators and defectors (Antal et al., 2009, Sigmund, 2009).

Empirical research suggests a central role for similarity-based assortment and cooperation in humans. A recent study found that participants cooperated more in a public goods game with individuals whose facial image had been morphed with their own than with individuals whose image had been morphed with that of another stranger (Krupp, Debruine, \& Barclay, 2008). A large body of research in psychology has further demonstrated the homophilic foundations of human groupishness and parochialism extending beyond the sphere of morphologically similar close kin (Bernhard, Fischbacher, \& Fehr, 2006, Billig \& Tajfel, 1973, Heyes, in press, Kinzler, Shutts, Dejesus, \& Spelke, 2009, Koopmans \& Rebers, 2009). In such scenarios, culturally acquired tags often serve as markers of shared social identity and group membership. 
Recently, some researchers have suggested that not all culturally acquired traits are created equally. Some traits, such as language and accent, are harder to fake than others and appear particularly wellsuited as guides to phenotypic assortment (Bernhard et al., 2006, Irwin, 1987, Kinzler et al., 2009, Nettle \& Dunbar, 1997, Roberts, 2008, Sigmund \& Nowak, 2001, Tooby \& Cosmides, 1989, Traulsen, 2008). Decades of sociolinguistic research have shown how accent, dialect, and language background powerfully guide evaluations and preferences in social interaction (e.g. Giles, 1977, Labov, 2001). Accent permits placement of individuals both geographically and in terms of social status, and strongly influences social perception and decisions about affiliation and potential for cooperation (e.g., (Trudgill, 2000). Preferential interaction with local, native-accented speakers over foreign-accented speakers emerges early in child development (Kinzler, Corriveau, \& Harris, 2011, Kinzler, Dupoux, \& Spelke, 2007) and accent appears to trump other salient cues to identity in children's social preferences - US 5-year-old children prioritized accent over race when choosing a friend (Kinzler et al., 2009). Children are also sensitive to linguistically marked status differences. A recent study found that multilingual South African children who attended Englishspeaking schools preferred speakers of English over speakers of their native Xhosa, a relatively much lower-status language (Kinzler, Shutts, \& Spelke, 2012). Accent thus appears to guide social assortment along at least two potentially fitness-relevant dimensions from early in development, reliably marking individuals in terms of similarity and status.

These findings have motivated broad claims about the evolutionary importance of accent as an assortative guide in affiliation and cooperation (Cohen, 2012). The apparent priority of accent over other salient markers of social identity so early in development has prompted the proposal that "accent is a privileged guide to cultural learning" and that "social preferences and reasoning based on accent may have origins in cognitive evolution"; specifically, "cognitive evolution may have favored attention to accent over other social variables (e.g., race) that would not likely have differed across neighboring groups in ancient societies" (Kinzler et al., 2011).

Several important empirical questions remain, however. First, to what extent do US children from monolingual families represent the broad human population (cross-culturally and for most of its history)? Two pieces of evidence warrant pause for thought. In systematic cross-cultural research across a wide range of behavioral and psychological domains, participants from Western populations (including the US), show up as outliers relative to the wider sample (Henrich, Heine, \& Norenzayan, 2010). The reasons for this are manifold and they vary according to the focus of investigation. In the case of sensitivity to linguistic variation, there is specific reason to assume that negligible exposure to linguistic varieties is indeed anomalous in the context of world cultures and human history. Migration, mobility, inter-group exchange, and exogamy are pervasive and ancient features of human society - most human communities are multilingual (or speak multiple dialects) and monolingualism is a relatively recent phenomenon (Lieberson, 1981). Perhaps the accent-guided social preferences of children from linguistic contexts characterized by regular exposure to diverse regional accents, dialects, or languages would be weaker or stronger than in largely monolingual populations, such as the US sample.

Second, a further question arises concerning the accent contrasts used. Arguably, second-language foreign-accented speech is not the most relevant contrast for an investigation of perceivers' responses to natural linguistic variations in the local population. Subtle regional variations potentially generate more or less striking effects in social preference (e.g., depending on acoustic distance between sounds, social relevance and familiarity, etc.). The use of second-language speakers further raises the possibility that perceiver preferences are driven by features of speech that have little to do with accent per se but rather with subtle cues to linguistic command or confidence generally. Contrasts using first-language, regional variations are needed to ascertain the importance of specifically accent variation as a guide to social preference.

Finally, is accent-guided social preference exhibited in measures of (costly) cooperation? Although choices about friendship alliances may be indicative of preferential willingness to cooperate, this inference has not been directly tested using standard measures of cooperation.

The present research sought to establish the empirical value of tagbased models in human cooperation and to address the above questions through an investigation of the role of accent in early developing cooperative behavior. We measured accent-guided friendship and cooperative preferences in 5-10 year old children in 4 Brazilian Amazonian towns (in Pará [PA] and Mato Grosso [MT] states). Two towns have a single dominant accent (Cachoeira do Ararí, PA; Jauru, MT) and two towns are characterized by accent diversity (Ulianópolis, PA; Canarana, MT). The multi-accent towns are relatively new towns, having been established from the 1960s partly through government incentives offered to prospective migrant landowners across the country. The towns continue to attract newcomers, maintaining accent variation through the generations. Local-accented speech varieties from each town were contrasted with unfamiliar, regional accented speech from Madeira (European Portuguese). European Portuguese was selected for its marked contrast with the Brazilian varieties as determined through phonetic comparison in prior work (Segura da Cruz \& Saramago, 1999). To avoid potential familiarity effects from standard European varieties, we used Madeiran Portuguese. Along with the Azores, Madeiran pronunciation reportedly differs most from the standard European accent. In a second study with a different group of age-matched participants, we assessed ability to discriminate between the two stimulus accents.

\section{Methods}

\subsection{Study 1}

\subsubsection{Participants}

479 children, aged 5-10, participated within state schools across the four sites (Cachoeira: 93, 39 males; Ulianópolis: 130, 62 males; Canarana: 120, 65 males; Jauru: 123, 67 males).

\subsubsection{Materials and design}

Participants were presented individually with 3 counterbalanced sharing trials and a final friendship trial. In each trial, participants made a forced choice between 2 individuals (presented as still images of identical puppets on a computer screen). One individual spoke with a native local accent (or, in the case of multi-accent towns, with the accent that matched that of the participant) and the other individual spoke, using the same statements, with a native Madeiran accent. Speech samples were pre-recorded with 10-11 yr-old children from each accent. The study was conducted by a native Brazilian female assistant from Belém, the capital city of the state of Pará.

The three sharing trials varied as follows;

- in the Equal trial, participants had the option of gaining a sweet and giving one sweet to either the local-accented individual (hereafter "Local") or the other-accented individual ("Other").

- in the Costly trial, participants chose between gaining one sweet and giving one to Local or gaining two sweets and giving one to Other.

- in the Unequal trial, participants had the option of gaining one sweet and either giving one sweet to Local or giving two sweets to Other.

In the final friendship trial, participants chose the puppet they would prefer as a friend. Though the same puppets and phrases were 

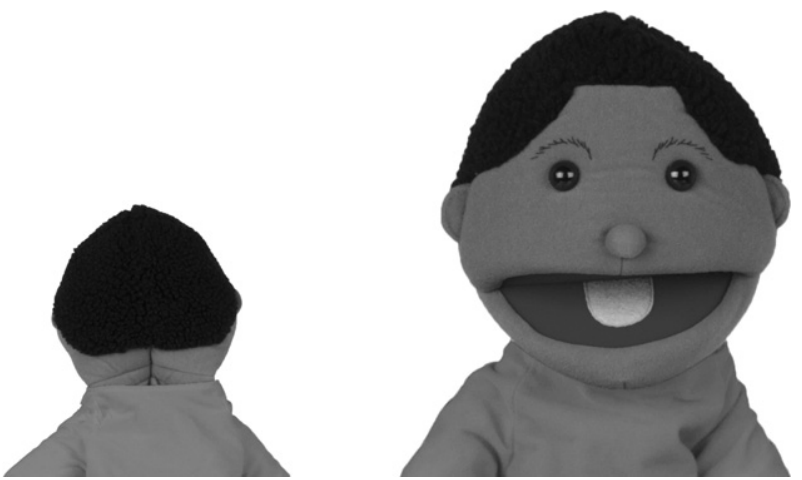

Fig. 1. Sample stimulus slide showing puppet on the right hand side speaking. Side of accent (Local or Madeiran Portuguese) and speaker order were counterbalanced across trials.

used across the three sharing trials, participants were informed at the start of each round that each puppet was a new individual. Phrases were presented counterbalanced for order and side (Figs. 1-3; see also Electronic Supplementary Material, available on the journal's Web site at www.ehbonline.org).

Puppets wore different colored t-shirts across rounds to emphasize the new identities. One methodological concern was that the novelty of this kind of task for our young rural Amazonian participants might have interfered with attention, distracting them from this instruction and from the game instructions generally. To assess attention and understanding we included a final question asking how many individuals had been presented (or, the children "had met") overall. Data from children who answered any number greater than four were retained for analysis (correct response: eight). This cut-off was established prior to analysis as the minimum expected response from a participant who had paid attention and understood that puppets across the sharing rounds were different individuals (although identical in appearance but for the t-shirt colours). A new pair of puppets was used in the final friendship round. An answer of five or more would therefore suggest that participants had accounted for the two puppets from the friendship trial and more than two puppets from the sharing trials. Insisting on a score of eight would have been over-conservative, especially for our younger participants, and was not necessary for the purposes of testing basic attention and understanding. For reference, we include pre-exclusion results alongside the main sub-set (post exclusion) analyses.

\subsubsection{Results}

28 out of 479 children were eliminated from analysis due to difficulty following the task instructions, experimenter error (in the
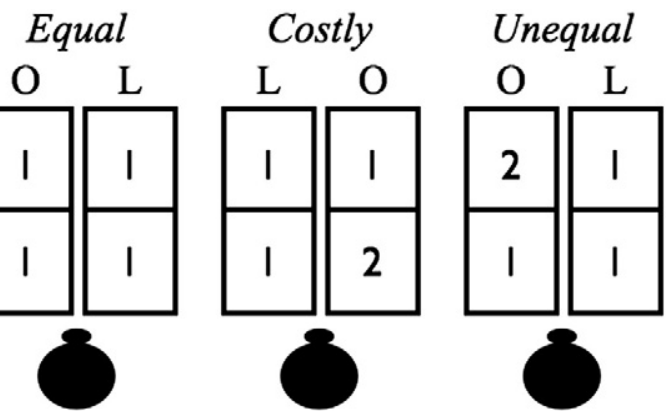

Fig. 2. Graphic displaying the two resource allocation options in the Equal, Costly and Unequal trials. Participants chose between sharing with the Local-accented (L) and Other-accented $(0)$ puppet.
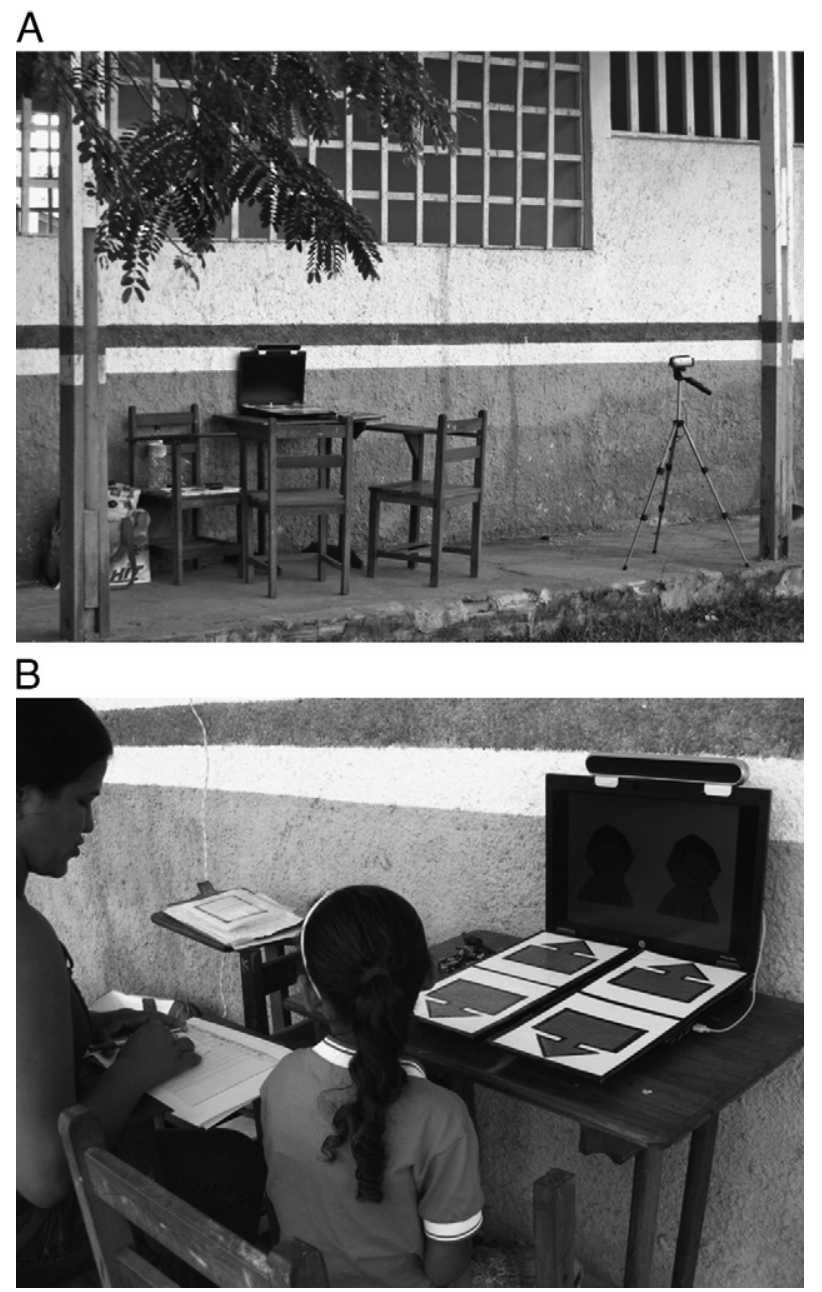

Fig. 3. Set-up and procedure. Plate A: A typical lab set-up (Cachoeira do Ararí). Plate B: Participants sat facing the laptop screen displaying two identical, but accentcontrasted, puppets. The cardboard trays displayed the resource allocation options for each round. The experimenter, who sat either to the child's right or left, presented the resource allocation options by placing sweets on the arrows. Participants indicated their preference by pulling toward them the tray displaying their preferred distribution.

placement of sweets), and general distractions and disruptions (from thunderstorms that made it impossible for the participant to hear the stimuli to interfering passersby, including wildlife); a further 145

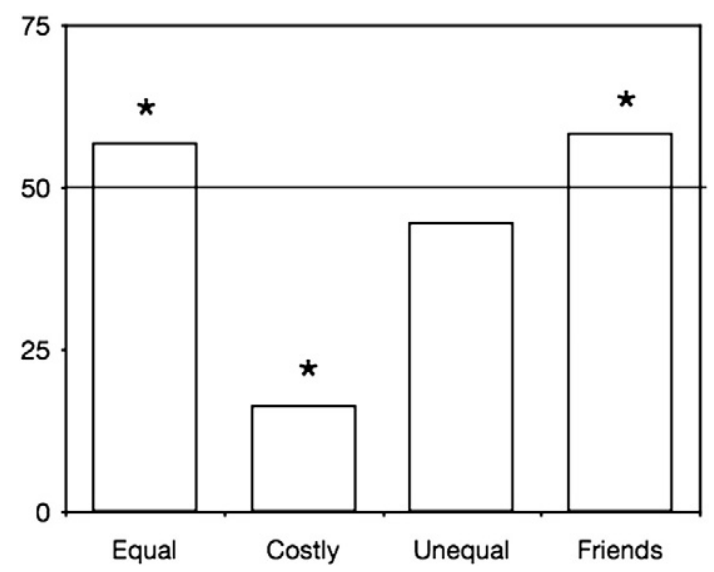

Fig. 4. Percentage preference for Local in Equal, Costly, Unequal, and Friendship trials (ages and sites collapsed). 
1

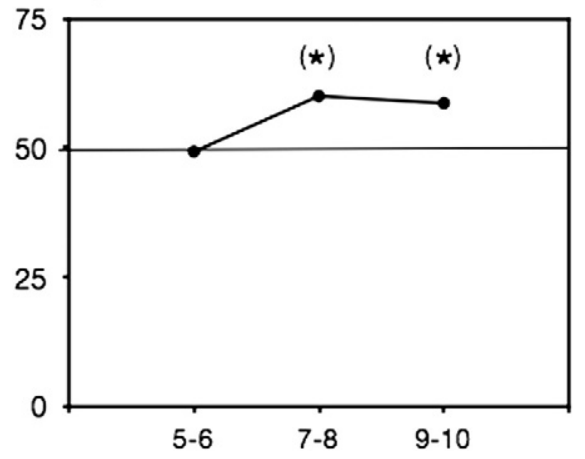

2

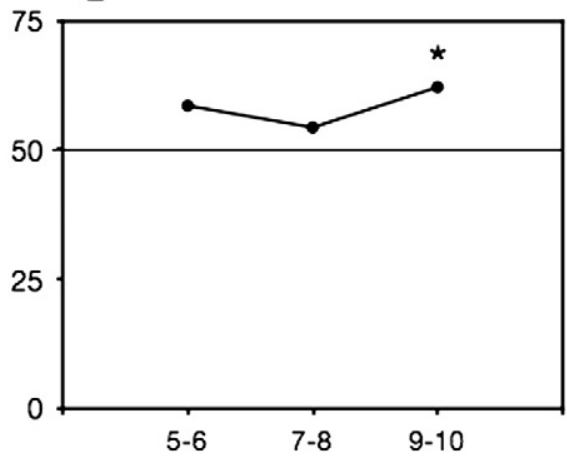

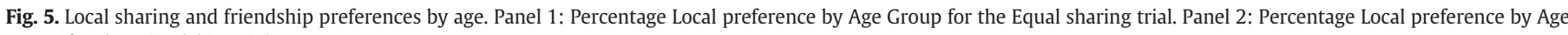
Group for the Friendship Trial.

participants answered four or less to the control question about the number of individuals presented, and 20 participants gave no response or an uncodable response (e.g. "don't know"). The final analysis includes the results from 286 children across the four sites ${ }^{1}$ (pre-exclusion, henceforth "PE", $n=451$ ).

In the Equal trial, there was a significant preference for Local among the reduced sample $(57 \%, p=.021,1$-sample binomial test; PE: $53 \%, p=.221)$, suggesting an accent-guided cooperative preference (Fig. 4). When a cost was introduced, however, children did not show a preference for Local. Rather, they preferred the option in which they gained two sweets and Other gained one (over a 1-1 split between Ego and Local; 83\%, $p<.001$; PE: $82 \%, p<.001$ ). There was no significant preference in the Unequal sharing trial. Taken together with the results of the Equal and Costly trials, this suggests that participants had no obvious bias toward more egalitarian distributions over "selfish" alternatives: an egalitarian bias or aversion to inequality, combined with the preference for Local (demonstrated in the Equal trial), would have predicted a preference for the 1-1 split with Local. Finally, in the Friendship trial, 58.4\% of participants preferred Local, again only in the reduced sample ( $p=.005$; PE: $53 \%$, $p=.53$ ). There were no significant sex differences in any trials.

Analyzing the results by site type, it appears that the preference for the Local speaker among the reduced sample is driven by participants from the multi-accent sites. Only this site type (Ulianópolis and Canarana data combined) shows a significant Local preference in the Equal sharing trial $(58.8 \%, N=160, p=.033,1$-sample binomial test against chance; PE: $55 \%, p=.109)$ and the Friendship trial $(61.3 \%, N=$ $126, p=.006$; PE: $55 \%, p=.141$ ) (Mono-accent sites: both trials $54.8 \%$ Local preference, $p=.33$; PE: $50 \%, p=1$ in Equal trial, $51 \%, p=.889$ in Friendship trial). Note, however, that there were no significant differences between sites or site types in the Equal and Friendship trials (chi-square test across sites: $\chi^{2}(3)=1.04, p=.79$ and $\chi^{2}(3)=$ $3.77, p=.29$; Fisher's exact test between site types, $p=.55$ and $p=.28$ (both 2-tailed), in Equal and Friendship trials respectively; PE: $\chi^{2}(3)=2.05, p=.56$ and $\chi^{2}(3)=1.62, p=.65$; PE Fisher's exact test between site types, $p=.30$ and $p=.39$ respectively). A further chisquare test confirmed no significant differences by stimulus accent presented (Equal trial, $\chi^{2}(4)=4.29, p=.37$; Friendship trial, $\chi^{2}(4)=$ $5.47, p=.24$, analyzing only those cases for which cell totals did not fall below 5; PE: Equal trial, $\chi^{2}(4)=3.16, p=.53$; Friendship trial, $\chi^{2}(4)=2.09, p=.72$ ), and a region-wise comparison also confirmed no significant differences between the sites closest to and farthest from Belém (Cachoeira and Jauru respectively) and between these sites and chance, suggesting that there was no systematic influence of experimenter accent on children's preferences in these towns (Fisher's

${ }^{1}$ Cachoeira: 51, 21 males; Ulianópolis: 89, 47 males; Canarana: 71, 38 males; Jauru: 75, 38 males. exact test, Equal: $p=.47$, Friendship: $p=.28$, 2-sided; binomial tests, all $p>.1$; PE: $p=.57$ and $p=.345$, respectively).

Analysis across age groups (5-6 [ $n=65], 7-8$ [ $n=105]$, and 9-10 $[n=116]$, sites collapsed) reveals a stronger Local preference in the older children (Fig. 5). Only the two older age groups show a trending preference for Local in the Equal sharing trial (age 5-6: 49.2\%, $p=$ 1.00; age 7-8: $60.0 \%, p=.05$; age $9-10: 58.6 \%, p=.08$; PE: age $5-6$ $(\mathrm{n}=151): 46 \%, p=.33$; age $7-8(\mathrm{n}=156): 56 \%, p=.17$; age $9-10$ $(\mathrm{n}=144): 58 \%, p=.08)$ and only the oldest group shows a significant Local friendship preference (5-6: $58.5 \%, p=.21 ; 7-8: 54.3 \%, p=.43$; $9-10: 62.1 \%, p=.01$; PE: age 5-6: $50 \%, p=1$; age $7-8: 51 \%, p=.94$; age $9-10: 58 \%, p=.055)$. Again, the preference patterns revealed among the oldest children appear to be driven by the multi-accent sites (both trials, $62 \%, p=.054$; mono-accent sites, both $p>.1$; PE: Equal, $60.7 \%, p=.06$; Friendship, 58.3\%, $p=.16$; mono-accent, 53.3\%, $p=.7$ and $58.3 \%, p=.245$, respectively).

The Costly and Unequal trials did not show a significant preference for the local-accented speaker. Nevertheless, these trials provide valuable evidence on participants' sensitivity to inequality. In the Costly trial, greater gain for self is consistently significantly preferred across all age groups and site types (all $>75 \%$ selfish/Other preference, $p<.01$, both reduced and PE samples). In the Unequal trial, compared with the youngest and oldest group, 7-8 year old participants appear to more strongly prefer Other (64.8\% Other preference, $p=.003 ; 5-6$ : 52.3\%; 9-10: 48.3\%; $\chi^{2}$ across the three age groups $(2, n=286)=$ $6.352, p=.042$; PE: $61.5 \%$ Other preference, $p=.005 ; 5-6: 62.9 \%, p=$ $.002 ; 9-10: 51.4 \% ; \chi^{2}$ across the three age groups $(2, n=451)=7.5$, $p=.024)$. Given the preference for Local in the Equal trial, this response seems to be driven primarily by a preference for more sweets overall regardless of the fact that neither Local nor Ego gains anything by this choice. Indeed, this preference for overall greater gain is stronger than the preference for Local and provides further evidence that participants are not inequality averse (irrespective of whether the greater gains go to self or other). Participants across all age groups showed no aversion to inequality in this task - youngest and oldest children were at chance in the Unequal trial $(47.7 \%$ and 51.7\% "Equal" response respectively; PE: youngest children also significantly chose the unequal option, $62.9 \% p=.002$; oldest children $48.6 \%$ Equal, $p=.80$ ).

To directly assess the degree to which children perceived accent differences, we conducted a further study with a different sample of age-matched participants across the four sites.

\subsection{Study 2}

\subsubsection{Participants}

Participants were a new sample of 243 5-10 year-old children drawn from the same school communities as in Study 1 (Cachoeira: 
63, 20 males; Ulianópolis: 57, 19 males; Canarana: 63, 29 males; Jauru: 60, 32 males).

\subsubsection{Materials and design}

Audio-visual stimuli from the three sharing trials in Study 1 were used. Children answered a series of three questions, one after each trial;

1. Which one speaks more similarly to you?

2. Which one speaks more differently from you?

3. Which one isn't from around here?

The order of the first two questions was counterbalanced across participants. The task and accompanying instructions were sufficiently simple to eliminate concerns about attention and understanding. Therefore, no additional attention/understanding measures were applied.

\subsubsection{Results}

Two participants from Canarana (one male and one female) and one female from Cachoeira were eliminated from analysis due to experimenter error (wrong accent recording used) and adverse listening conditions (thunderstorm), respectively; two male participants from Canarana and one male from Ulianópolis were eliminated due to difficulties in following task instructions (final $N$ for analysis $=238$ ).

A mean correct score for the three responses was calculated and scores were compared across site types and age groups. To assess the effects of both region and site type, we conducted a $2 \times 2$ betweensubjects ANOVA with site type (mono-accent and multi-accent) and site region (North $[N=118]$ : Cachoeira do Ararí and Ulianópolis; South $[N=120]$ : Canarana and Jauru) as factors. This revealed an effect of site type $\left(F_{1,234}=11.55, p<.001, n_{p}^{2}=.05\right)$ : the combined mean score of the multi-accent sites was higher than the combined mean score of the mono-accent sites $(2.02(S D=.838)$ and $1.61(S D=$ .978 ) respectively), suggesting that participants who are more frequently exposed to accent variations were better able to distinguish between the contrasting accents and to distinguish non-local speakers from local speakers. There was no effect of site region $\left(F_{1}, 234=0.022, p=.881\right)$ and no site type by region interaction $\left(F_{1,234}=0.025, p=.873\right)$. This suggests that differences in discrimination abilities are not attributable to any disparity in the degree of contrast between stimulus accents across sites. Such an interpretation would predict effects by geographic (and therefore accent) region.

Analysis of the developmental trajectory of these effects suggests that sensitivity to ambient accent variation emerges by age $7-8$. There is no difference between mean scores of the youngest children in mono and multi accented sites (or of either group compared to chance; $1.58(S D=.75 ; N=40)$ and $1.5(S D=.934 ; N=40)$ respectively). The 7-8 yr old group showed significant differences across site types: while children from mono-accented sites remained at chance $(M=1.51, S D=.81, N=41)$, the multi-accented sample had a significantly higher mean score of 2.10 (independent t-test between groups: $t(80)=-3.064, N=41, p=.003, d=0.685$; one-sample t-test, compared to chance: $t(40)=-4.174, p<.001, d=1.32$ ). At age $9-10$, the gap in scores increased further, with the mono-accented sample remaining statistically at chance (mono accented sample, 1.76 $(\mathrm{SD}=.943, N=41)$; multi-accented sample, $2.51(S D=.818)$; independent t-test: $t(74)=-3.712, N=35, p<.001, d=0.86)$. These results suggest that the significant Local-accent preference in sharing (Equal trial) and friendship choices in multi-accented sites owes, at least in part, to a more sensitively tuned ear for accent variation.

\section{Discussion}

In line with earlier findings among US samples, our results suggest that accent guides children's early developing social preferences. This is the case not only for friendship choices but also for decisions about sharing. These effects appear to be primarily driven by the data from the multi-accented sites - analysis by site type revealed a significant preference for the local accent in the multi-accented sites only (Equal and Friendship trials). This finding may be linked to differences in exposure to accent varieties. Even though children's own accent was contrasted with a non-local regional accent with which participants had no known familiarity, children from the multi-accented sites discriminated among speakers significantly more accurately than did children from the mono-accented sites. Analysis by region does not support an interpretation in terms of accent distance - using region as a proxy for accent disparity with the Madeiran contrast, we found no differences in preference patterns between the two northern and the two southern sites. Open questions remain concerning the mechanism whereby exposure leads to an own-accent preference. Basic competence in perceptual discrimination among accents is clearly important, but explaining the direction of the preference (for own-accent rather than other-accent) requires further research into the effects of familiarity and the specific socio-political meanings of accent distinctions within the local community (e.g. according to status, class, etc.), and the dissociations and interactions between familiarity and similarity in children's accentbased social preferences.

Comparison across age groups revealed that friendship and sharing preferences increased with age. A significant Local sharing preference emerged by age 7-8 (Equal trial) and a significant Local friendship preference by age 9-10. Irrespective of site-type, 5-6 year old Brazilian children did not show a significant local accent preference, contrasting with the results of Kinzler et al. (2007). Overall, the local accent preference among the Brazilian participants appears weak in comparison with the US samples. Further research is required to ascertain the degree to which this may be due to cultural differences between the two populations (e.g. in education, language environment, etc.) or methodological differences in the study set-up (e.g. foreign-accent vs. regional accent contrasts). Alternatively, it may be that young Chicago children, though raised in mono-lingual environments, are exposed to a wider range of accents than are children from the relatively smaller and more provincial Brazilian mono-accent sites and this may encourage a native/local accent preference (as appears to the case in our multi-accent sites). Further research is required across a range of linguistic and demographic settings to explore how children's developing social preferences are tuned according to locally relevant dimensions of social variation (linguistic, class-based, racial, etc.; see Kinzler \& DeJesus, in press).

The Costly sharing trials further showed that, in the face of costs to self, the Local preference did not persist; the significant preference for selfish gain effectively shifted the sharing preference from Local to Other. More surprisingly, in light of children's Local preference in the Equal trial as well as previous findings on early-emerging parochial inequity aversion among Swiss children (Bernhard et al., 2006), participants showed no preference for a 1(Ego)-1(Local) over a 1(Ego)-2(Other) allocation of resources (Unequal trial). To summarize, participants showed two clear sharing preferences: a local accent preference and a selfish-gain preference. When pitted against each other, however, selfish gains prevailed.

The basic sharing and friendship preferences revealed here, although not sufficiently strong to withstand costs to self, are broadly supportive of an early emerging accent-based selection bias guiding assortment among potential cooperative partners. Notably, however, this bias appears to be tuned according to locally relevant environmental parameters. Further research is required to systematically investigate the ontogeny and relative roles of similarity-based judgments across a range of observable and variable traits (e.g., skin color), and their relative influence across diverse environments (e.g., racially homogeneous and heterogeneous sites). More generally, there is considerable scope for a program of empirical research on 
both proximate and ultimate mechanisms in tag-based scenarios, and for concerted cross-disciplinary investigation of the affordances and constraints of culture for the emergence and maintenance of tagbased cooperation in humans (Bernhard et al., 2006).

\section{Supplementary Material}

Supplementary data to this article can be found online at http://dx. doi.org/10.1016/j.evolhumbehav.2013.02.001.

\section{Acknowledgments}

We thank Andrezza Barbosa for assistance with data collection across all Brazilian sites. For their contributions to preparation of materials and for field assistance, we thank Glaciele Ferreira de Abreu, Antonio Aroca, Darlice Ribeiro da Costa, Juliane Dauksch, Jan Keil, Sandy Kennert, Vanise Muribeca, Sylvio Tüpke and Luisa Soares.

\section{References}

Antal, T., Ohtsuki, H., Wakeley, J., Taylor, P. D., \& Nowak, M. A. (2009). Evolution of cooperation by phenotypic similarity. Proceedings of the National Academy of Sciences of the United States of America, 106, 8597-8600.

Bernhard, H., Fischbacher, U., \& Fehr, E. (2006). Parochial altruism in humans. Nature, 442, 912-915.

Billig, M., \& Tajfel, H. (1973). Social categorization and similarity in intergroup behaviour. European Journal of Social Psychology, 3, 27-52.

Cohen, E. (2012). The evolution of tag-based cooperation in humans: The case for accent. Current Anthropology, 53, 588-616.

Fletcher, J. A., \& Doebeli, M. (2009). A simple and general explanation for the evolution of altruism. Proceedings of the Royal Society of London B Biological Sciences, 276, 13-19.

Giles, H. (1977). Language, ethnicity and intergroup relations. New York: Academic Press.

Henrich, J., Heine, S. J., \& Norenzayan, A. (2010). Beyond WEIRD: Towards a broadbased behavioral science. The Behavioral and Brain Sciences, 33, 111-135.

Heyes, C. (2013). What can imitation do for cooperation? In B. Calcott, R. Joyce, \& K. Sterelny (Eds.), Signalling, commitment and cooperation. Cambridge, MA: MIT Press.

Irwin, C. J. (1987). A study in the evolution of ethnocentrism. In V. Reynolds, V. S. E. Falger, \& I. Vine (Eds.), The sociobiology of ethnocentrism (pp. 131-156). London: Croom Helm.
Jansen, V. A. A., \& van Baalen, M. (2006). Altruism through beard chromodynamics. Nature, 440, 663-666.

Kinzler, K. D., Corriveau, K. H., \& Harris, P. L. (2011). Children's selective trust in nativeaccented speakers. Developmental Science, 14, 106-111.

Kinzler KD, DeJesus JM. (2012). Northern = smart and Southern = nice: The development of accent attitudes in the U.S. Quarterly Journal of Experimental Psychology. [online before press].

Kinzler, K. D., Dupoux, E., \& Spelke, E. S. (2007). The native language of social cognition. Proceedings of the National Academy of Sciences of the United States of America, 104, 12577-12580.

Kinzler, K. D., Shutts, K., Dejesus, J., \& Spelke, E. S. (2009). Accent trumps race in guiding children's social preferences. Social Cognition, 27, 623-634.

Kinzler, K. D., Shutts, K., \& Spelke, E. S. (2012). Language-based social preferences among children in South Africa. Language Learning and Development, 8, 215-232.

Koopmans, R., \& Rebers, S. (2009). Collective action in culturally similar and dissimilar groups: An experiment on parochialism, conditional cooperation, and their linkages. Evolution and Human Behavior, 30, 201-211.

Krupp, D. B., Debruine, L. A., \& Barclay, P. (2008). A cue of kinship promotes cooperation for the public good. Evolution and Human Behavior, 29, 49-55.

Labov, W. (2001). Principles of linguistic change, vol. 2: Social factors. Malden, CA: Blackwell.

Lieberson, S. (1981). Language diversity and language contact: essays. Stanford, CA: Stanford University Press.

Masuda, N., \& Ohtsuki, H. (2007). Tag-based indirect reciprocity by incomplete social information. Proceedings of the Royal Society of London B Biological Sciences, 274 689-695.

Nettle, D., \& Dunbar, R. I. M. (1997). Social markers and the evolution of reciprocal exchange. Current Anthropology, 38, 93-99.

Riolo, R. L., Cohen, M. D., \& Axelrod, R. (2001). Evolution of cooperation without reciprocity. Nature, 414, 441-443.

Roberts, G. (2008). Language and the free-rider problem: An experimental paradigm. Biological Theory:, 174-183.

Segura da Cruz, M. L. \& Saramago, J. (1999). Acores e Madeira: Autonomia e coesão dialectais. In I. H. Faria (Ed.), Lindley Cintra. Homenagem ao homem, ao mestre e ao cidadão (pp. 706-738). Lisboa: Cosmo.

Sigmund, K. (2009). Sympathy and similarity: The evolutionary dynamics of cooperation. Proceedings of the National Academy of Sciences of the United States of America, 106, 8405-8406.

Sigmund, K., \& Nowak, M. A. (2001). Tides of tolerance. Nature, 414, 403-404.

Tooby, J., \& Cosmides, L. (1989). Kin selection, genic selection, and informationdependent strategies. The Behavioral and Brain Sciences, 12, 542-543.

Traulsen, A. (2008). Mechanisms for similarity based cooperation. European Physical Journal B, 63, 363-371.

Trudgill, P. (2000). Sociolinguistics: An introduction to language and society. London: Penguin. 